\title{
Preference and sensory factors in brightness discrimination learning of posterior neodecorticated albino rats
}

\author{
LOIS O. STRATTON and SUSAN EDWARDS \\ Louisiana State University in New Orleans, New Orleans, La. 70122
}

Albino rats preferred the dark areas in a free choice situation, and preference was enhanced at high differential brightness levels. Posterior neodecortication did not reduce dark preference significantly, as it does in hooded rats. Learning was retarded when ablated albinos were forced to approach a high intensity light in the T-maze apparatus. With low illumination, sensory and preference factors were balanced so that scores of light-and dark-positive rats were nearly identical.

A reduction in light aversion following posterior neodecortication has been observed in the normally dark-preferring rat, and increased light preference explains the early superior performance of posteriors on a light-dark problem, with light as the positive cue (Krechevsky, 1936; Horel et al, 1966; Spear \& Braun, 1969). However, posterior rats may approach a light stimulus simply because it is the most distinctive cue in their visual field. Most discrimination learning st udies have used the Thompson-Byrant box (1955), where spatial cues are minimized by proximal placement of right-left choices. Bauer $\&$ Cooper (1964) found that posteriors are deficient in sensory capacity and can only solve a brightness task when high differential light levels are used. In an open-field test, posteriors were less light sensitive than normals, but they failed to show the light preference noted in learning studies (Altman, 1962). If light preference responding is due primarily to orientation toward the most distinctive environmental cue, then posteriors should not differ greatly from normals in a learning task where the differential cues are made optimally discriminable by maximum displacement in space. Also, high levels of light should prove aversive to the posterior rat, as is characteristic of the species. The following two studies evaluated the dark preference of posteriors and normals and assessed the effect of preference on learning in a T-maze apparatus. EXPERIMENT 1:

\section{PREFERENCE TESTING}

Subjects and Apparatus

The Ss were 24 male albino Sprague-Dawley rats, 100-130 days old at the time of testing. Twelve Ss were assigned randomly to either a high or low light-intensity group, and half of the Ss from each group received bilateral posterior neodecortication by the suction method under sodium nembutal anesthesia. Postmortem histological examination showed that Krieg's (1946) Areas 17, 18, 18a, and parts of 7 and 36 were removed, as seen in Fig. 1. Operates were given 2 weeks to recover from surgery before testing began.

The animals were tested in the arms of a Plexiglas-enclosed T-maze with grid floor. A detailed description of the apparatus may be found in Thompson et al (1961). Two 20-W cool white fluorescent bulbs, placed 5 in. from the back of the apparatus, illuminated the length of each alley and goalbox, and light intensity was regulated by a variable autotransformer. Lighting for each alley was wired independently. Lights were encased in separate wood containers to minimize spread of light, and a sheet of milk glass was placed in front of each section to reduce glare. A light meter, placed at rat-eye level between the alleys and facing a lighting section, registered $1.2 \mathrm{fc}$ for the low-intensity stimulus, 9-10 fc for the high-intensity situation, and $0 \mathrm{fc}$ for the dark alley.

\section{Procedure}

Animals were preference tested $5 \mathrm{~min}$ a day for 6 days. Room lights were turned of $f$, and one or the other alley was illuminated according to a Gellerman series. The Ss were initially placed in the center of the horizontal section of the T-maze, facing the lighting attachment. Ss were scored for the number of seconds spent in the dark and light arms of the apparatus. Time in a neutral area (defined as that part of the alley in front of the startbox) was not recorded. Number of crossings from one section to the other were also counted.

\section{Results}

A Ss/Groups by Trials analysis of variance was performed on the preference data. Time spent in the dark and light were treated as "trials" since they represented correlated measures. There was no difference between operates and normals at either level of illumination (Fig. 2).

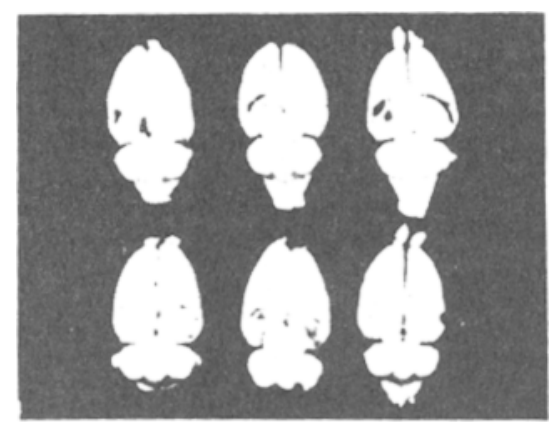

Fig. 1. Representative posterior lesions chosen at random. 


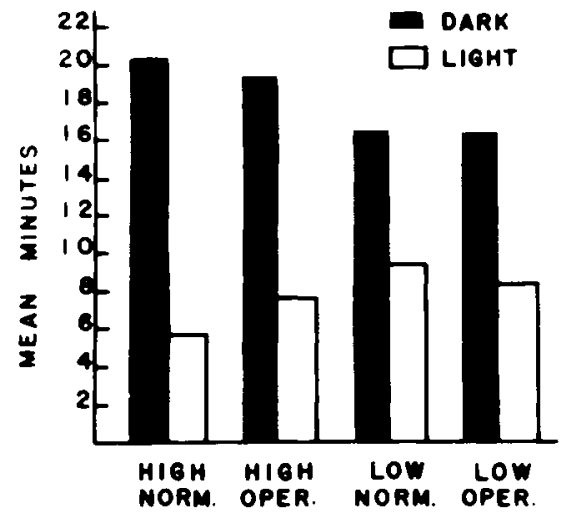

Fig. 2. Mean time spent in dark and light sectors of the T-maze for normal (norm) and operated (oper) animals under high - or low-intensity conditions.

Time spent in the dark was greater than time spent in the light at both differential levels of illumination $(p<.01)$, and time in the dark was greater at the high than at the low light intensity $(p<.01)$. Data on the number of crossings showed that operates crossed more often than normals and were more active on the third and fourth days of testing than on Days 1 and $2(\mathrm{p}<.05)$. EXPERIMENT 2:

\section{LIGHT-DARK DISCRIMINATION} Subjects and Apparatus

The Ss were $24 \mathrm{male}$ Sprague-Dawley rats, $160-200$ days old at the time of testing. The animals were all subjected to posterior neodecortication, as described in Experiment 1 . Histological examination revealed that one $S$ had extensive bilateral hippocampal damage and another had a grossly asymmetrical cortical lesion. These 2 Ss were eliminated from the study, and the data analysis was performed on the remaining 22 Ss.

The apparatus was the same one used in Experiment 1; however, the grid floor was now electrified and escape from shock was the motive for learning. Plexiglas doors, painted black, were placed at the goalbox entrances and could be pushed aside for entry. The two goalbox grids were wired independently, and these extended 5 in. in front of the goalbox entrance.

\section{Procedure}

Following a 2-week recovery from surgery, Ss were trained to open goalbox doors under room light conditions by placing the doors at an angle and gradually narrowing the aperature. After door training was accomplished, each $\mathrm{S}$ was given six trials a day on the problem, with a $30-\mathrm{sec}$ ITI to a criterion of $11 / 12$ correct responses. The low-intensity lighted alley (1-2 fc) was positive for Group LL (low light), and the high intensity alley $(9-10 \mathrm{fc})$ was positive for Group HL (high light). The dark-positive groups were designated LD (low dark) and HD (high dark), according to the intensity of the negative stimulus. The positive cue was alternated according to a Gellerman series. A response to the positive stimulus admitted $S$ to the goalbox, whereas a response within $5 \mathrm{in}$. of the negative goalbox resulted in footshock and confrontation with a locked goalbox door. An error was recorded when S's foot came in contact with the negative grid.

Results and Discussion

The two-way ANOVA revealed a significant stimulus effect $(p<.05)$ and a significant Stimulus by Intensity interaction $(p<.05)$. In the high-intensity condition, light-positive rats made nearly nine times as many errors as did dark positives $(\mathrm{HL}=\mathbf{2 9 . 5}$, $H D=3.3$ ), while at low intensity the performance of $L$ and $D$ Ss was nearly identical $(L D=13.3, L L=13.0)$.

All Ss preferred the dark arms of the T-maze in the free choice situation, and preference was greater at higher light levels. Under high illumination, posterior rats showed a nominal, but insignificant, shift toward the light, when compared to normals. This contrasts with Altman's (1962) findings for hooded rats, which show a significant light preference following posterior ablation. Since lack of pigmentation of the iris limits the albino's ability to attenuate the intensity of retinal stimulation (Chorover \& Chase, 1968), a bright source would prove more noxious to albino than to hooded Ss. Ablation, on the other hand, elevates sensory threshold in both strains. Since albinos were impaired in learning at high, but not low, levels of illumination, some balance of aversiveness and threshold was apparently obtained in the low condition.

Lashley (1935) reported that posterior rats learned a brigh tness task with equal ease before and after posterior ablation, but subsequent investigators have reported that operates suffer losses of attention (Krechevsky, 1936), tend to perseverate position habits (Horel et al, 1966), and evidence increased locomotor activity (Lewellyn et al, 1969; Altman, 1962; this study), in addition to their sensory deficiencies. Presumably, light-approach behavior compensated for these other deficiences in Lashley's animals. Meyer et al (1966) found that posterior albinos were inferior to hoodeds in relearning a brightness problem which they attributed to an inferior "residual" CNS. The present study suggests that albinos are discouraged from light approach by their inability to attenuate light input, whereas hoodeds are predisposed to light approach after ablation. Light intensity is a critical factor in visual learning, interacting with strain of rat and threshold sensitivity. The evidence suggests that posterior rats orient to light at low intensity, but at higher intensity the light becomes aversive to the albino, but not the hooded.

\section{REFERENCES}

ALTMAN, J. Effects of lesions in central nervous visual structures on light aversion of rats. American Journal of Physiology, 1962, 202, 1206-1210.

BAUER, J. H., \& COOPER, R. M. Effects of psoterior cortical lesions on performance of a brightness-discrimination task. Journal of Comparative \& Physiological Psychology, 1964, 58, 84-92.

CHOROVER, S. L., \& CHASE, R. Persistence of visual pattern discrimination in binocularly occluded albino rats. Journal of Comparative \& Physiological Psychology, 1968, 65 . 238-245.

HOREL, J. A., BETTINGER, L. A. ROYCE, J. C., \& MEYER, D. R. Role of the neocortex in the learning and relearning of two visual habits by the rat. Joumal of Comparative \& Physiological Psychology, 1966, 61, 66-78.

KRECHEVSKY, 1. Brain mechanisms and brightness discrimination learning. Journal of Comparative Psychology, $1936,21,404-445$.

KRIEG, W. J.S. Connections of the cerebral cortex: 1 . The albino rat: A. Topography of the cortical areas. Journal of Comparative Neurology, 1946, 84, 221-275.

LASHLEY, K. S. The mechanism of vision: $X I I$. Nervous structures concerned in the acquisition and retention of habits based on reactions to light. Comparative Psychology Monograph, 1935, 11 . No. 52, 43-79.

LEWELLYN, D., LOWES、G., \& ISAACSON, R. L. Visually mediated behavior following neocortical destruction in the rat. Journal of Comparative \& Physiological Psychology, 1969, 69, 25-32.

MEYER, D. R. YUTZEY, D. A., \& MEYER, P. M. Effects of neocortical ablation on relearning of a black-white discrimination habit by two strains of rats. Journal of Comparative \& Physiological Psychology, 1966, 61, 83-86.

SPEAR. P. D.. \& BRAUN, J, J Nonequivalence of normal and posteriorly neodecorticated rats on two brightness discrimination problems. Journal of Comparative \& Physiological Psychology, 1969, 67, 235-239.

THOMPSON, R., \& BYRANT, H. J. Memory as affected by activity of the relevant receptor. Psychological Reports, $1955,1,393-400$.

THOMPSON, R., DUKE, R. B., MALIN, C. F. \& HAWKINS, W. F. The interpeduncular nucleus and retention in albino rats. Journal of Comparative \& Physiological Psychology, 1961, 54. 329-333. 